\title{
Atlanto-Occipital Synostosis in a Colombian Population Sample
}

\author{
J.E. Duque Parra ${ }^{1,2}$ J. Barco Ríos ${ }^{2}$ J.F. García Aguirre ${ }^{1,2,3}$ \\ ${ }^{1}$ Laboratory of Neurophysiology, Departamento de Ciencias Básicas \\ Biológicas, Facultad de Salud, Universidad Autónoma de Manizales, \\ Caldas, Colombia \\ 2 Department of Basic Sciences, Programa de Medicina, Facultad de \\ Ciencias para la Salud, Universidad de Caldas, Manizales, \\ Caldas, Colombia \\ 3 Programa de Medicina, Universidad de Manizales, Manizales, \\ Caldas, Colombia
}

J Morphol Sci 2018;35:28-30.

\begin{abstract}
Address for correspondence J.F. García Aguirre, MD, Universidad de Manizales, Street 18 9-03, 170017, Manizales, Caldas, Colombia (e-mail: jofe16@gmail.com).
\end{abstract}

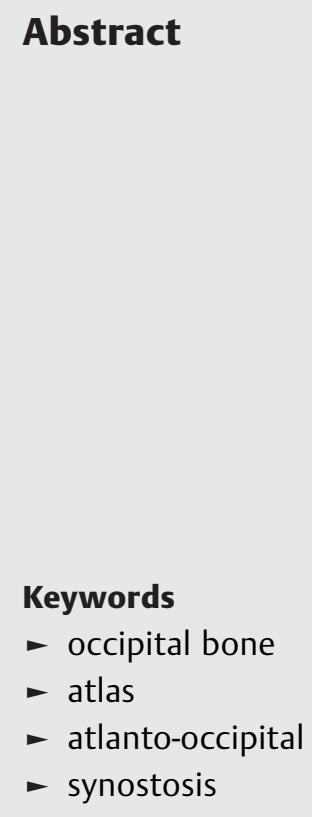

Introduction The Cervico-capital rotation process involves important joints with respect to the neurological field. Among these joints, the atlanto-occipital joint accounts for $40 \%$ of the total rotation process and its anatomical changes may affect the joint, i.e when the synostosis of both bones occurs. This anomaly has a reported incidence in the world population of $0.14 \%$ to $0.75 \%$. To determine whether this incidence range also corresponds to the Colombian population, atlanto-occipital fusion in Colombian patients was studied.

Materials and Methods The presence of atlanto-occipital fusion was assessed in a random sample of 105 skulls of a Colombian population. Morphometric features were evaluated by using a Vernier caliper.

Results Out of the total sample two cases of atlanto-occipital fusion were identified. One of them exhibited a bilateral fusion between the anterior arch of the foramen magnum and the lateral masses of the atlas; the other one exhibited a left hemisynostosis that compromises the anterior arch foramen magnum and left lateral mass of atlas. The overall frequency of occurrence was $1.9 \%$.

Conclusion A greater incidence of atlanto-occipital fusion was found in contrast to the range of world incidence reported in the literature.

\section{Introduction}

Knowledge of cranio-vertebral abnormalities and their morphology is important for clinicoradiological studies. This leads to clinical assessments with more accurate diagnoses, as in those cases where synostosis is present, i.e the atlantooccipital fusion that affects the mentioned joint and that is formed by the junction between the lateral mass superior articular facet of the atlas and the corresponding occipital condyle. The atlanto-occipital membrane joins these two bones. ${ }^{1}$ The atlanto-occipital joint is a synovial joint with a loose and thin articular capsule. Atlanto-occipital synostosis is defined as a congenital fusion of the atlas to an occipital base. ${ }^{2,3}$ This anomaly was first described by Rokitansky in 1884 , and since then, several terminologies such as synostosis, occipitalization of Atlas, fusion of atlanto-occipital or ankylosis of atlanto-occipital fusion have been used. ${ }^{2}$

Cervico-capital rotation process involves important joints with respect to the neurological field. Among these joints, the atlanto-occipital joint accounts for $40 \%$ of the total rotation process, ${ }^{4}$ and anatomical changes may affect the joint i.e when synostosis of both bones occurs. This anomaly has a $0.14 \%$ to $0.75 \%$ of reported incidence in world population. ${ }^{2}$ Different received

January 18,2017

accepted

February 7, 2018
DOI https://doi.org/

$10.1055 / \mathrm{s}-0038-1660486$. ISSN 2177-0298.
Copyright (e) 2018 by Thieme Revinter

Publicações Ltda, Rio de Janeiro, Brazil
License terms

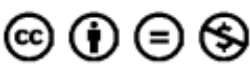


varieties of this anomaly have been described. These include complete or incomplete types, complete synostosis being the most common. ${ }^{5}$ Synostosis may be associated with other skeletal malformations, such as spina bifida of atlas, occipital vertebra, basilar invagination, Klippel-Feil syndrome, ArnoldChiari malformation and cervical stenosis. ${ }^{6}$

Knowledge of atlanto-occipital synostosis is important from the clinical point of view due to the vertebral artery position and the first spinal nerve (C1). Vertebral artery compression may cause a cerebral blood flow (CBF) decrease and $\mathrm{C} 1$ compression can cause neurological symptoms as well. ${ }^{7}$ Different clinical manifestations of this synostosis have been described, namely cephalea, cervical pain, abnormal neck position anomalies, decreased range of movement, dizziness, dysphagia and dysarthria. ${ }^{8}$

\section{Materials and Methods}

This was an observational and cross-sectional study with a descriptive coverage. Quantitative and qualitative information was collected. 105 adult skulls without reported injury of the occipital region were randomly selected. These skulls belonged to the Departments of Anatomy of Caldas, Manizales and Autonoma universities. The presence of synostosis between the occipital bone and C1 was assessed. There was no distinction between ethnicity or sex. Among exclusion criteria were those skulls with presence of trauma or gross malformations in the cervico-occipital region. Synostosis was assessed between the occipital bone and the $\mathrm{C} 1$. A Vernier caliper and a camera were used for morphometric descriptions.

\section{Results}

Out of 105 skulls studied, 1.9\% showed synostosis between the lower portion of the occipital bone and the C1. One of skulls had complete synostosis and another one hemisinostosis, as follows.

Skull 1 exhibited a hemisinostosis between the occipital bone and the first cervical vertebra ( $\mathrm{C} 1$ ), characterized by complete fusion on the right side and incomplete fusion on the left side (-Figs. 1 and 2). This region did not exhibit posterior condyloid foramina (-Fig. 2). This suggests the presence of synostosis in corresponding ducts of the emissary veins within the sigmoid sinus. On the right side, a developed channel between the lateral mass and the lateral occipital bone was observed, which makes way for the course of the right vertebral artery. Its diameter was $4.5 \mathrm{~mm}$ at its greatest end and $2.5 \mathrm{~mm}$ at its lowest end. On the left side, a lateral mass fusion of the vertebrae $\mathrm{C} 1$ with occipital bone was observed. The transverse foramen and the extra space makes way for the course of the left vertebral artery. Its diameter was $4.5 \mathrm{~mm}$ at its greatest end and $2 \mathrm{~mm}$ at its lowest end. The anterior tubercle of $\mathrm{C} 1$ vertebra showed no synostosis with the occipital bone. However, it was deviated from the median line of $4 \mathrm{~mm}$, with reference to the pharyngeal tubercle (-Fig. 1).

Skull 2 exhibited a bilateral synostosis between the occipital bone and the first cervical vertebra (C1) (- Figs. 3

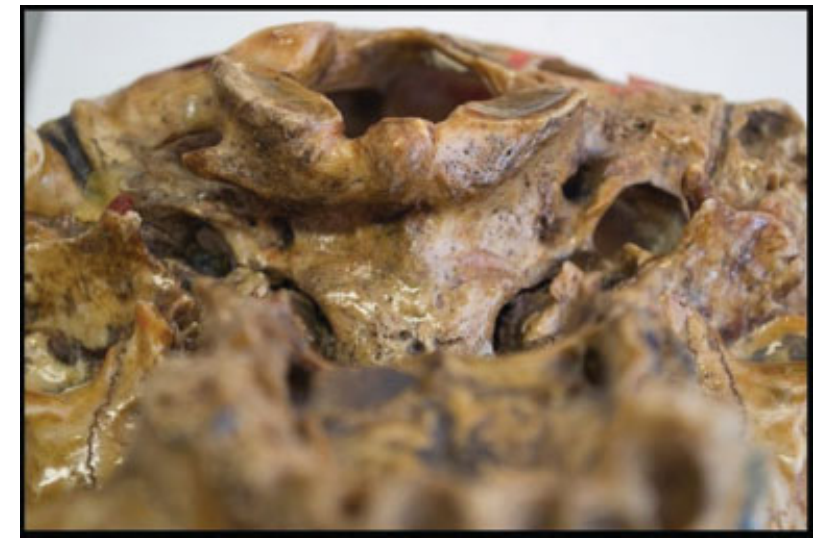

Fig. 1 (Standard basal skull with C1 and occipital synostosis. Synostosis on the right side of the lateral masses and hemisinostosis on the left side is highlighted.

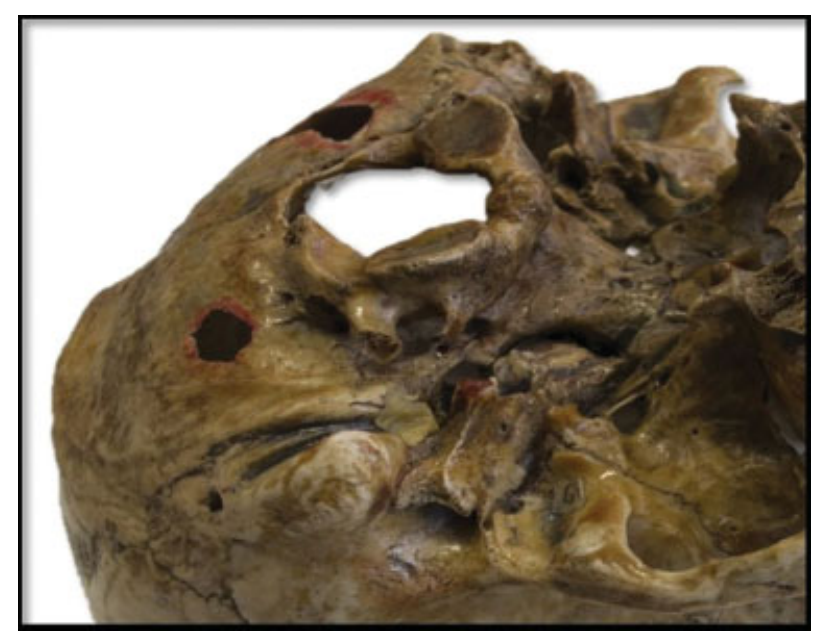

Fig. 2 Incomplete synostosis between $\mathrm{C} 1$ and occipital bone.

and 4). This region presented no posterior condyloid foramina, which suggests the presence of synostosis in corresponding ducts of emissary veins within sigmoid sinus, similarly to case 1 . On the left side, a developed channel

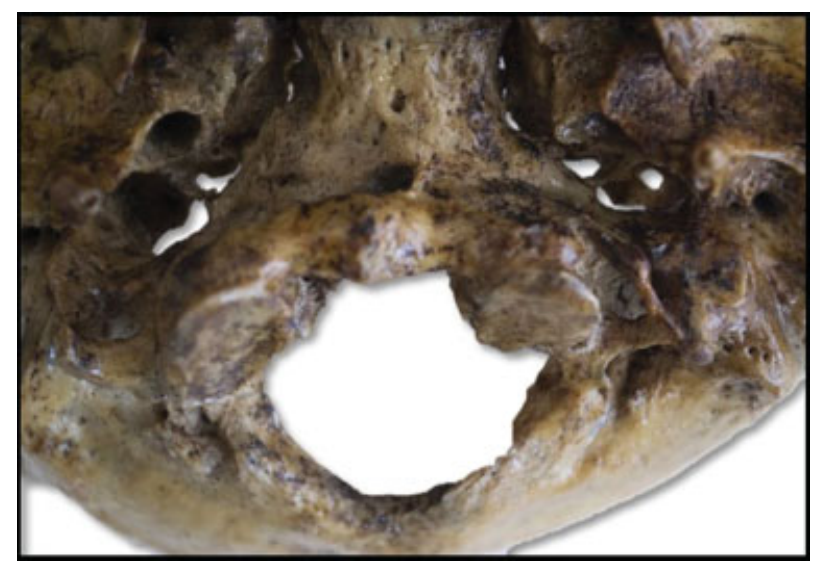

Fig. 3 Complete synostosis: in a standard basal skull, a deviation of the above process $\mathrm{C} 1$ to the right side is noted. Intrajugular process fused with occipital bone is also noted. This divides jugular foramen into two. 




Fig. 4 Complete synostosis.

between lateral mass and occipital bone is identified which makes way for the course of the left vertebral artery. Its diameter was $6 \mathrm{~mm}$ at its greatest end and $5 \mathrm{~mm}$ at its lowest end. On the right side, there was a complete fusion of the lateral mass that prevented the development of the $\mathrm{C} 1$ foramen transversarium. This suggests that the artery had an intracranial course from the $\mathrm{C} 2$ foramen transversarium. The anterior tubercle of $\mathrm{C} 1$ suffered no synostosis with the occipital, although it was deviated from the midline, $1.5 \mathrm{~mm}$, with reference to the pharyngeal tubercle.

\section{Discussion}

The frequency of atlanto-occipital synostosis in this study was $1.9 \%$. This is significantly higher compared with the information reported in the literature, which references values in range from 0.14 to $0.75 \%{ }^{9-11}$

In the skull with hemisinostosis, the reduced diameters of the small ends of the ducts formed by the passage of the vertebral artery in its exocraneal course lead to a suspected blood flow decrease due to stenosis of both arteries. This is due to the contrasting values of the diameter of the vertebral artery reported in the literature from 3.5 to $4 \mathrm{~mm} .^{12}$ This would affect the movement of the anterior, posterior, inferior posterior, cerebellar and basilar arteries. On the other hand, the skull with atlanto-occipital bilateral synostosis shows a transverse foramen diameter within normal parameters in its left side, in contrast to the right side transverse agenesis foramen which suggests that the vertebral artery undergoes no narrowing in its course toward the inside of the skull after piercing the atlantoaxial membrane.

Atlas deviations of the anterior tubercle suggest an asymmetrical cruciate ligament, since the fovea for the odontoid process moves unilaterally. This could have generated instability on the atlantoaxial joint. The case of bilateral synostosis in one of the skulls is related to a deep invagination of the basilar region, consistent with reports in the literature. ${ }^{6}$

\section{Conclusion}

In a direct morphological study in skulls of a Colombian sample, it was determined that the frequency of the atlantooccipital synostosis is higher by $253 \%$ compared with that reported in the literature. This type of synostosis alters the occipital and spinal region morphologically and can generate variations in the course of the vertebral artery compatible with some clinical manifestations.

\section{Acknowledgments}

The authors want to thank Monica Naranjo Ruiz and Rose May Lamber Delamare, from the Translation Center of the Autonoma University of Manizales, for the translation of this article.

\section{References}

1 Pró EA. Anatomía clínica. Buenos Aires: Editorial Médica Panamericana; 2012:963

2 Mudaliar RP, Shetty S, Nanjundaiah K, Kumar J P, Kc J. An osteological study of occipitocervical synostosis: its embryological and clinical significance. J Clin Diagn Res 2013;7(09): 1835-1837

3 Vasudeva N, Choudhry R. Precondylar tubercles on the basiocciput of adult human skulls. J Anat 1996;188(Pt 1):207-210

4 Duque Parra JE, Barco Ríos J, Moscoso Ariza OH. Grados de rotación cérvico-capital de la población de Caldas, Colombia. Int J Morphol 2010;28(04):1125-1129 Doi: 10.4067/S071795022010000400022

5 Kayhan B, Ilhan P, Ertürk M, Şengül G. Occipitocervical synostosis: case report. Anatomy: Intern J Experim Clin Anatom 2015; 9:104-107

6 Saini V, Singh R, Bandopadhyay M, Tripathi SK, Shamal SN. Occipitalization of the atlas: its occurrence and embryological basis. Intern J Anatom Variat 2009;2:65-68

7 Goel A, Sharma P, Dange N, Kulkarni AG. Techniques in the treatment of craniovertebral instability. Neurol India 2005;53 (04):525-533 Doi: 10.4103/0028-3886.22625

8 Campos DD, Silva TH, Ellwanger JH, et al. Atlanto-occipital fusion and its neurological complications: a case report. J Morpho Sciences 2012;29(02):111-113

9 Guebert GM, Yochum TR, Rowe LJ. Congenital anomalies and normal skeletal variants. Essentials of skeletal radiology. Baltimore: Lippincott Williams \& Wilkins; 1987:1680

10 Monalisa Pandit S, Bhatnagar R. Atlanto-occipital fusion: a case report. Medical Journal of Dr. D.Y. Patil Vidyapeeth 2015;8(05): 636 10.4103/0975-2870.164963

11 Von Torklus D, Gehle W. The upper cervical spine: regional anatomy, pathology, and traumatology: a systematic radiological atlas and textbook. New York: Grune \& Stratton; 1972:101

12 Pereira-Recio H. Estado actual del ultrasonido Doppler de las arterias vertebrales. Revista Archivo Médico de Camagüey 2008; 12:10-15 